\title{
RESEARCH
}

Open Access

\section{Hippocampal interleukin-33 mediates neuroinflammation-induced cognitive impairments}

Flora Reverchon ${ }^{1,2}$, Vidian de Concini ${ }^{1}$, Vanessa Larrigaldie ${ }^{1}$, Sulayman Benmerzoug ${ }^{1,3}$, Sylvain Briault ${ }^{1,4}$, Dieudonnée Togbé ${ }^{\prime}$, Bernhard Ryffel', Valérie F. J. Quesniaux ${ }^{1}$ and Arnaud Menuet ${ }^{1 *}$

\begin{abstract}
Background: Interleukin (IL)-33 is expressed in a healthy brain and plays a pivotal role in several neuropathologies, as protective or contributing to the development of cerebral diseases associated with cognitive impairments. However, the role of IL-33 in the brain is poorly understood, raising the question of its involvement in immunoregulatory mechanisms.

Methods: We administered recombinant IL-33 (rmlL-33) by intra-hippocampal injection to C57BL/6 J (WT) and IL1 a deficient mice. Chronic minocycline administration was performed and cognitive functions were examined trough spatial habituation test. Hippocampal inflammatory responses were investigated by RT-qPCR. The microglia activation was assessed using immunohistological staining and fluorescence-activated cell sorting (FACS).

Results: We showed that IL-33 administration in mice led to a spatial memory performance defect associated with an increase of inflammatory markers in the hippocampus while minocycline administration limited the inflammatory response. Quantitative assessment of glial cell activation in situ demonstrated an increase of proximal intersections per radius in each part of the hippocampus. Moreover, rmlL-33 significantly promoted the outgrowth of microglial processes. Fluorescence-activated cell sorting analysis on isolated microglia, revealed overexpression of IL-1 $\beta, 48 \mathrm{~h}$ post-rmIL-33 administration. This microglial reactivity was closely related to the onset of cognitive disturbance. Finally, we demonstrated that IL-1a $\beta$ deficient mice were resistant to cognitive disorders after intrahippocampal IL-33 injection.
\end{abstract}

Conclusion: Thus, hippocampal IL-33 induced an inflammatory state, including IL-1 $\beta$ overexpression by microglia cells, being causative of the cognitive impairment. These results highlight the pathological role for IL-33 in the central nervous system, independently of a specific neuropathological model.

Keywords: Interleukin-33, Interleukin-1, Microglia, Memory

\footnotetext{
*Correspondence: menuet@cnrs-orleans.fr

Flora Reverchon and Vidian de Concini are co-first authors.

'UMR7355, Experimental and Molecular Immunology and Neurogenetics,

CNRS and University of Orléans, 3B rue de la Ferollerie, 45071 Orléans, France

Full list of author information is available at the end of the article
}

C C The Author(s). 2020 Open Access This article is licensed under a Creative Commons Attribution 4.0 International License, which permits use, sharing, adaptation, distribution and reproduction in any medium or format, as long as you give appropriate credit to the original author(s) and the source, provide a link to the Creative Commons licence, and indicate if changes were made. The images or other third party material in this article are included in the article's Creative Commons licence, unless indicated otherwise in a credit line to the material. If material is not included in the article's Creative Commons licence and your intended use is not permitted by statutory regulation or exceeds the permitted use, you will need to obtain permission directly from the copyright holder. To view a copy of this licence, visit http://creativecommons.org/licenses/by/4.0/. The Creative Commons Public Domain Dedication waiver (http://creativecommons.org/publicdomain/zero/1.0/) applies to the data made available in this article, unless otherwise stated in a credit line to the data. 


\section{Introduction}

IL-33 is a member of the interleukin-1 (IL-1) cytokine family that plays important roles in various disorders including allergy, autoimmune, or cardiovascular diseases through its receptor ST2 and co-receptor IL-1 accessory protein (IL-1RAcP) [1]. Recently, IL-33 has also been involved in the pathogenesis of central nervous system (CNS) diseases such as neurodegenerative diseases, stroke, or infectious diseases. Broadly and highly expressed in the CNS in physiological conditions, IL-33 is described as a key regulator of neuroinflammation [2-4].

In experimental autoimmune encephalomyelitis (EAE), a model of multiple sclerosis disease (MS), a systemic administration of recombinant IL-33, from the day of immunization until day 18 , induces a protective effect [5]. However, the intraperitoneal administration of antiIL-33 neutralizing antibodies also delayed the onset and the severity of EAE [6]. These apparently opposite findings highlight the dual function of IL-33. Moreover, this dual function of IL-33 has also been observed in Alzheimer's disease (AD). IL-33 is highly expressed in the vicinity of amyloid plaques and in glial cells in brain sections from AD patients suggesting that a prolonged IL-33 production may induce inflammatory molecule release and contribute to the $\mathrm{AD}$ pathogenesis with neuronal damage [7]. However, more recently, Saresella et al. [8] demonstrated a decrease of IL-33 in the serum of AD patients as compared with healthy controls. These clinical data highlight a complex pro- and antiinflammatory properties of IL-33 in AD patients acting both at the central and systemic level. IL-33 dual functions have also been observed in CNS infectious diseases. We previously reported the essential role of the IL-33 receptor ST2 in the pathogenesis of experimental cerebral malaria (ECM) caused by Plasmodium berghei Anka (PbA)-infection in mice. We showed that ST2deficient mice were resistant to $\mathrm{PbA}$-induced neuropathology [9] and demonstrated a deleterious role of CNS endogenous IL-33 in the neuropathogenesis associated with cognitive disorders [10]. Surprisingly, IL-33 deficient mice were not resistant to ECM [11] and IL-33 systemic administration improved antimalarial drug treatment of ECM via Treg cells [12, 13]. Thus, IL-33 has dual effects on infection, inflammation, and diseases of the CNS [1] raising the question of the cellular and immunomodulators involved.

Immunohistological analyses and IL-33/citrine reporter mice showed that astrocytes [14, 15] and oligodendrocytes $[10,16]$ are the main cellular sources of IL-33 within the CNS. Moreover, ST2 receptor is overexpressed by astrocytes and microglial cells under pathophysiological conditions [14]. Microglia could be the first glial cells to respond to IL-33 stimulation through the ST2/IL-1RAcP receptor complex [15]. We previously showed a deleterious effect of CNS endogenous IL-33 through the activation of microglia leading to IL- $1 \beta$ release in ECM [10]. IL-33 is not only involved $[15,16]$ but essential for the microglial activation [17]. Given the importance of microglia in the neurotoxic or neuroprotective inflammatory responses, CNS IL-33 may be a key factor in the neuroinflammatory processes and associated with cognitive impairments.

In this study, we show that recombinant mouse IL-33 administration in the hippocampus led to microglial cell activation and increased IL-1 production associated with cognitive disturbance.

\section{Materials and methods}

\section{Mice and ethics statement}

C57BL/6 J (wild-type; WT) male mice under specific pathogen-free (SPF) condition at 8 weeks of age were purchased from Janvier Labs (Le Genest Saint Isle, France). Mice deficient for both IL- $1 \alpha$ and IL-1 $\beta$ were bred in the Transgenose Institute animal facility (CNRS UPS44, Orleans, France). They were issued from an intercross between IL-1 $\alpha \mathrm{KO}$ and IL-1 $\beta$ KO mice [18]. As they were backcrossed 10-fold on C57BL/6 J background, C57BL/6 J control was used. Mice were housed at four per propylene cage with woodchip bedding, and kept under controlled conditions of temperature (20$22^{\circ} \mathrm{C}$ ), humidity $(50 \%)$, and bright cycle (12/12-h dark/ light), with free access to chow pellets and water. The animals were previously habituated to our animal facility at 4 weeks and used in experimental settings at 8 weeks of age. All animal experimental protocols complied with the French ethical and animal experiments regulations (see Charte Nationale, Code Rural R 214-122, 214-124 and European Union Directive 86/609/EEC) and were approved by the "Ethics Committee for Animal Experimentation of CNRS Campus Orleans" (CCO), registered $\left(\mathrm{N}^{\circ} 3\right)$ by the French National Committee of Ethical Reflexion for Animal Experimentation, under $\mathrm{N}^{\circ}$ CLE CCO 2015-1084 and by the French "Ministère de l'enseignement supérieur, de la recherche et de l'innovation", under number APAFIS \#19264.

\section{Intrahippocampal microinjection}

Mice divided into 4 groups, received intrahippocampal injections of either vehicle PBS containing $0.1 \%$ BSA as a carrier (PBS-BSA) or recombinant mouse (rm) IL-33 protein (R\&D Systems, Abingdon, UK; $200 \mathrm{ng} / \mu \mathrm{l}$ in PBSBSA), in the absence or in the presence of minocycline hydrochloride (MP Biomedicals, Illkirch, France) was administered daily (i.p, $50 \mathrm{mg} / \mathrm{kg}$ in $\mathrm{NaCl} 0.9 \%$ ) during 10 days, including 7 days before surgery and 3 days postsurgery. Before intrahippocampal injections, mice anesthetized with ketamine/xylazine $(100 \mu \mathrm{L} / 10 \mathrm{~g}$ i.p. of 29.4 
$\mathrm{mg} / \mathrm{mL}$ ketamine plus $3.05 \mathrm{mg} / \mathrm{mL}$ xylazine) were secured in the stereotaxic apparatus (KOPF instruments, Lidingö, Sweden). Burr holes were drilled bilaterally in the skull above the hippocampus at $2.0 \mathrm{~mm}$ posterior to bregma, and $\pm 1.8 \mathrm{~mm}$ lateral to bregma. Then, mice received bilateral intrahippocampal injection of rmIL-33 protein at $400 \mathrm{ng}$ in a total volume of $2 \mu \mathrm{L}$ of PBS-BSA by side. Control animals received PBS-BSA vehicle. A $10-\mu \mathrm{L}$ Hamilton syringe (Hamilton, Reno, NV, USA) controlled by a Stereotaxic Injector (KD Scientific, Holliston, USA) was used to inject the solution at a rate of $0.25 \mu \mathrm{L} / \mathrm{min}$ in the hippocampus at $-1.80 \mathrm{~mm}$ to Bregma. After the surgery and to facilitate recovery, each mouse was placed alone per cage until the end of the experiments. Groups of sham animals were subjected to a similar hippocampal surgery, without PBS-BSA or rmIL-33 injection with or without minocycline pretreatment.

\section{Spatial habituation test}

Spatial habituation to a novel environment is commonly used for the exploration of non-associative learning and memory processes linked to hippocampal structures [19-21]. As previously described [22], to explore the learning component, 1 day after the surgical intervention, the animal was allowed to explore an open field (OF) $(40 \mathrm{~cm} \times 40 \mathrm{~cm})$ for $10 \mathrm{~min}$ (trial session). After 24 $\mathrm{h}$, the mouse was re-exposed for $10 \mathrm{~min}$ to the same OF (test session). During each session, the exploratory measures were quantified using the Ethovision tracking system (version 10, Noldus Technology, Wageningen, Netherlands). Locomotor activity was indexed by the distance traveled in the entire open-field arena. To explore intrasession habituation during the trial session, the distance traveled between the first and the last minute was compared. The intersession habituation was assessed by comparing the full distance traveled during both sessions. All sessions were performed at 10 lux to limit the anxiogenic component of the novel environment.

\section{Real-time quantitative polymerase chain reaction (RT- qPCR)}

At the indicated time, total RNA from the hippocampus was isolated using TRI-Reagent (Sigma-Aldrich, SaintQuentin Fallavier, France) as previously described [10] and reverse transcripted (Superscript III reverse transcriptase, Invitrogen, Carlsbad, CA). Quantitative realtime PCR reactions were performed using GoTaq qPCRMaster Mix (Promega, Charbonnières-les-Bains, France) and primers for Nos2, Il1b, Tnfa, Ifng, Arg1, Chil3, Illo, and Igf1 (Qiagen, Hilden, Germany). After normalization using 18S-RNA expression as a housekeeping gene, raw data were analyzed by the $2^{\Delta \Delta C t}$ method [23].

\section{Tissue preparation and immunofluorescence}

For immunostaining, mice were deeply anesthetized and transcardially perfused with ice-cold PBS followed by $4 \%$ paraformaldehyde (PFA). The brains were collected, post-fixed for $48 \mathrm{~h}$ in $4 \%$ PFA, and cryo-protected in a $30 \%$ sucrose solution for 1 week. Then, $14 \mu \mathrm{m}$ brain cryo-sections mounted onto glass slides were incubated in citrate buffer $(\mathrm{pH}=6)$ at $80^{\circ} \mathrm{C}$ for $30 \mathrm{~min}$, followed by incubation with blocking solution (TBS 1X; 1\% BSA; $10 \%$ FCS; $0.3 \%$ Triton; $1 \%$ NaN3) during $45 \mathrm{~min}$ in a wet chamber at room temperature. After incubation overnight at $4{ }^{\circ} \mathrm{C}$ with anti-Iba- 1 antibody (Abcam, Cambridge, England, ab5076; 1:500), the sections were washed in TBS and incubated with Alexa 488 secondary antibody (Abcam, ab150129, 1:1000) for $1 \mathrm{~h}$. The slides were rinsed, then counter-stained with DAPI for $10 \mathrm{~min}$, mounted with Fluoromount-G (SouthernBiotech, Birmingham, England), and dried before observation using ZEISS AXIOVERT $200 \mathrm{M}$ /Apotome microscope (Zeiss, Oberkochen, Germany). Serial sections were collected at $\times 20$ magnification to reconstruct each whole-hippocampal image software (ZEN2.1, Zeiss). The images were collected as Z-series of 18 optical slices to obtain a sufficient resolution to perform the morphological analysis of microglial cells. For each mouse, 3 representative stacks of images of the hippocampus were recorded. Positive cells for Iba-1 were counted (50-100 cells) and their morphology analyzed in each area e.g. the cornu ammonis (CA)1/CA2, CA3 and the dentate gyrus (DG). Image analysis and processing were performed with the software Image J -Fiji [24] using the "concentric circles" plugin. For the Sholl analysis, the intersection number per radian was defined each $5 \mu \mathrm{m}$ from the center of each cell $(n=3$ mice per treatment with 50-100 microglia analyzed per mouse). This analysis was performed by a blinded experimenter.

\section{Fluorescence-activated cell sorting}

The hippocampus of 3 mice perfused with phosphatebuffer saline (PBS) was pooled and the cellular suspensions were prepared using the Neural Tissue Dissociation Kit (Miltenyi Biotec, Paris France), according to the manufacturer's instructions. Cells were stained with extracellular conjugated antibodies: Fixable Viability Dye (eBiosciences $^{\mathrm{TM}}$, 65-0865-14, 1/800), anti-CD45 V450 (BD Horizon $^{\mathrm{TM}}$, 560501, 1:100), anti-CD11b PerCP/Cy5 (BD Pharmingen $^{\mathrm{TM}}$, 560993, 1:100) and blocked with non-

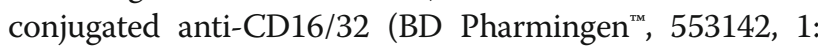
100 ) for $20 \mathrm{~min}$ at $4{ }^{\circ} \mathrm{C}$. Then, the cells were washed before fixation. Intracellular IL-1 $\beta$ pro-form stained with PE-conjugated specific antibody (eBioscience ${ }^{\mathrm{Tm}}, 12-7114-$ 80, 1:20) was visualized after cell permeabilization for 20 min at $4{ }^{\circ} \mathrm{C}$ with Cytofix/Cytoperm Plus Kit (BD Biosciences, Paris, France). This antibody recognizes only the 
pro-form of mouse IL-1 $\beta$ and does not detect the cleaved and secreted mature IL- $1 \beta$ form. Cells were then washed and re-suspended in lysing solution (BD FACS ${ }^{\mathrm{m}}$ Lysing Solution) before the acquisition. Data were acquired with a flow cytometer (BD FACSCanto II) and analyzed with FlowJo v7.6.5 software (Tree Star, Ashland, OR). Very low SSC and very low FSC were excluded to strictly define the populations of interest. IL- $1 \beta$ pro-form staining was measured using geometric mean fluorescence intensity (GMFI). For the analysis, live single cells were pre-gated.

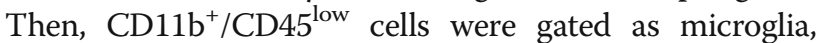

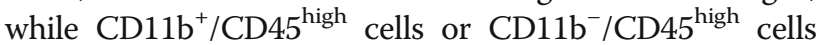
were gated as infiltrating macrophage or lymphocyte cells, respectively. FMO controls were also included to define populations of Fixable Viability Dye cells and CD45, CD11b, and IL-1 $\beta$-expressing cells.

\section{Statistical}

Statistical significance was determined with GraphPad Prism v6 (GraphPad Software, La Jolla, CA). Standard errors of the mean are reported as SEM. To analyze non-parametric data, Mann-Whitney test for 2 series was used or Kruskal-Wallis followed by Dunn's multiple comparison for more series. $P$ values $\leq 0.05$ were considered statistically significant.

\section{Results}

Local hippocampal rmlL-33 injection impairs long-term memory

We previously proposed a role for IL-33/ST2 signaling pathway in the hippocampus in the cognitive impairments after $P b A$-infection, especially on the memory process [10]. In this respect, we asked whether CNS IL33 overexpression, mimicked here by an exogenous rmIL-33 administration locally in the hippocampus, could influence cognitive functions. After bilateral intrahippocampal injections of rmIL-33 or vehicle, nonassociative learning and memory retrieval processes were explored by spatial habituation test in an openfield apparatus as described in Fig. 1a. The time spent in the central square was similar in all tested groups 24 $\mathrm{h}$ post-surgery (Addition file 1), suggesting an absence of specific anxiogenic response. The total distance traveled $24 \mathrm{~h}$ post-surgery decreased from 1-10 min during the first session in a novel environment for both vehicle- and rmIL-33-treated mice (Fig. 1b), corresponding to appropriate habituation to spatial novelty. The total distance traveled during the test session at $48 \mathrm{~h}$ was significantly reduced in the vehicle group, as compared with the training session at $24 \mathrm{~h}$, indicating a normal ability to retrieve the previous exploratory information from memory processes, e.g., a proper long-term habituation process (Fig. 1c). In contrast, rmIL-33-treated mice showed no reduction of distance traveled at $48 \mathrm{~h}$, as compared with the $24 \mathrm{~h}$ training session, indicative of a disturbed long-term habituation process (Fig. 1c). These findings showed that rmIL-33 hippocampal administration impaired spatial memory retrieval processes.

\section{Minocycline prevents the long-term memory impairment induced by rmIL-33}

IL-33 is considered as an immunomodulator of various neuropathologies [2]. To investigate the impact of the immune response on rmIL-33-induced cognitive impairment, minocycline which is an anti-inflammatory antibiotic able to cross the blood-brain barrier [25] was used. Minocycline pre-treatment was administrated daily, starting 7 days prior to vehicle and rmIL-33 intrahippocampal administration. In our experimental conditions (Fig. 1a), minocycline treatment did not affect anxiogenic response to a novel environment (Addition file 1). In addition, habituation to spatial novelty in vehicle or rmIL-33-treated animals during the trial session was also conserved (Fig. 1d). In contrast, the impairment of long-term habituation previously observed after rmIL-33 administration (Fig. 1c) was absent in minocycline-treated animals (Fig. 1e). Indeed, mice receiving minocycline treatment showed a decrease in distance traveled at $48 \mathrm{~h}$ compared with the distance traveled at $24 \mathrm{~h}$ even after rm-IL-33 administration. These data thus suggest that minocycline treatment prevents the deleterious effect of rmIL-33 administration on spatial memory retrieval. These data demonstrate that minocycline should prevent the deleterious effect of rmIL-33 administration on spatial memory retrieval.

\section{IL-33 drives inflammatory response in the hippocampus}

We next asked whether the effect of minocycline on restoring rmIL-33-induced cognitive impairment may be associated with its reduction of a neuroinflammatory response [25]. We evaluated the time course of neuroinflammatory processes in the hippocampus $24 \mathrm{~h}$ and $48 \mathrm{~h}$ after a single injection of rmIL-33 alone or in the presence of minocycline pre-treatment in the hippocampus (Fig. 2). The slight increase in pro-inflammatory markers expression seen at $24 \mathrm{~h}$ post-injection in terms of Nos 2 , Il1b, Tnfa, Ifng (Fig. 2a to d), as well as antiinflammatory markers Arg1, Chil3, Il10 and Igf1 (Fig. 2e to $h$ ) was observed both in vehicle- and rmIL-33-treated mice, as compared with the sham group, suggesting an inflammatory response to the microinjection itself. This inflammatory response was resolved at $48 \mathrm{~h}$ in vehicletreated control animals, returning to the level of the sham group. However, at $48 \mathrm{~h}$, a time point corresponding to the cognitive impairment, rmIL-33-treated mice showed high levels of hippocampal expression of 


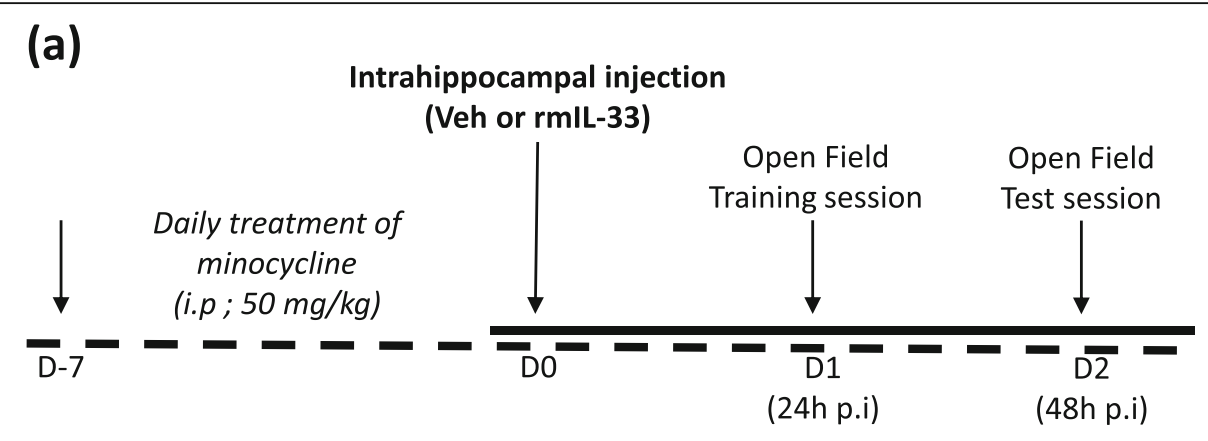

(b)

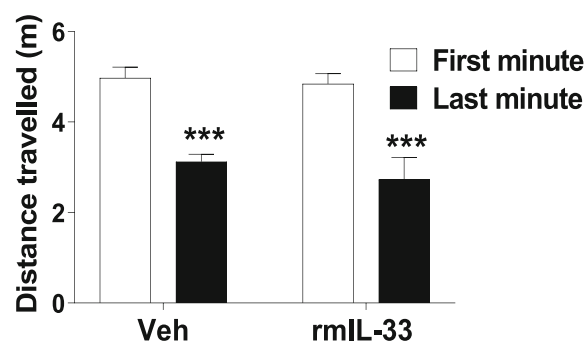

(d)

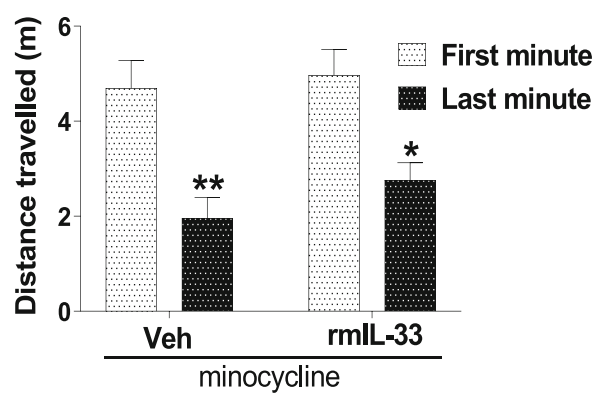

(c)

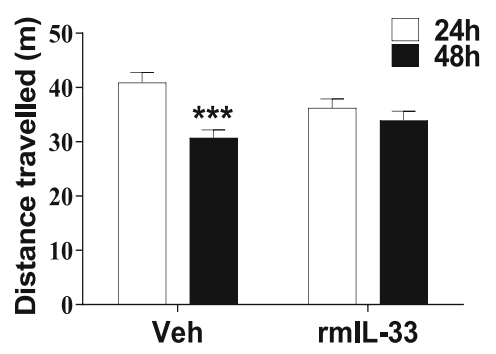

(e)

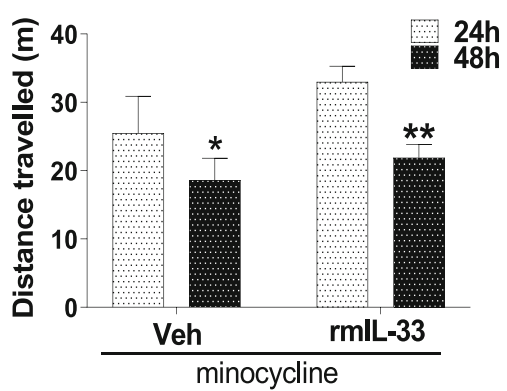

Fig. 1 Effect of hippocampal exogenous IL-33 associated with minocycline pre-treatment on spatial memory and habituation. a Experimental design. Mice were intrahippocampally injected with rmIL-33 or vehicle solution (PBS-BSA 0.1\%). The cognitive behavior was tested on day 1 by a first open-field session, followed by a second session on day 2. The short term habituation was analyzed during the first session on day 1 . $\mathbf{b}$ and d The distance traveled between the first and the last minute in the open-field were compared. $\mathbf{c}$ and $\mathbf{e}$ The long-term habituation was accessed by comparing the distance traveled between the first session ( $24 \mathrm{~h})$ and the last session ( $48 \mathrm{~h}$ ). Two cohorts have been studied: (b and $\mathbf{c})$ vehicle or rmlL-33 treated without minocycline, (d and e) vehicle or rmlL-33 treated with minocycline. Under our experimental conditions, IL-33 impaired the intersession habituation $(\mathbf{c})$. This effect on spatial memory retrieval was prevented by minocycline administration (e). Values are mean \pm SEM, $n=8-15$ per group corresponding to a pool of 2 independent experiments. Two-way ANOVA followed by a Sidak post hoc test was used to analyze the distance traveled among groups. ${ }^{*} P \leq 0.05,{ }^{* *} P \leq 0.01,{ }^{* *} P \leq 0.001$

inflammatory markers, as compared with the vehicle group. Thus, rmIL-33 administration delayed the resolution of inflammation. Interestingly, minocycline treatment reduced the expression of $I l 1 b$ and Ifng observed $48 \mathrm{~h}$ after the rmIL-33 administration (Fig. 2b, d) while it had no effect on the other parameters studied. Thus, minocycline treatment partially reduces the deleterious effects of rmIL-33 on the resolution of inflammation by limiting the overexpression of $I l 1 b$ and Ifng. We must notice that Illa expression analysis showed a similar response to $I l 1 b$ but fold inductions were widely reduced (Addition file 2).

Intrahippocampal administration of rmIL-33 exacerbates microglial activation

To further analyze IL-33 implication in the inflammatory processes, we next investigated the effect of rmIL-33 on microglia $48 \mathrm{~h}$ after intrahippocampal administration. 


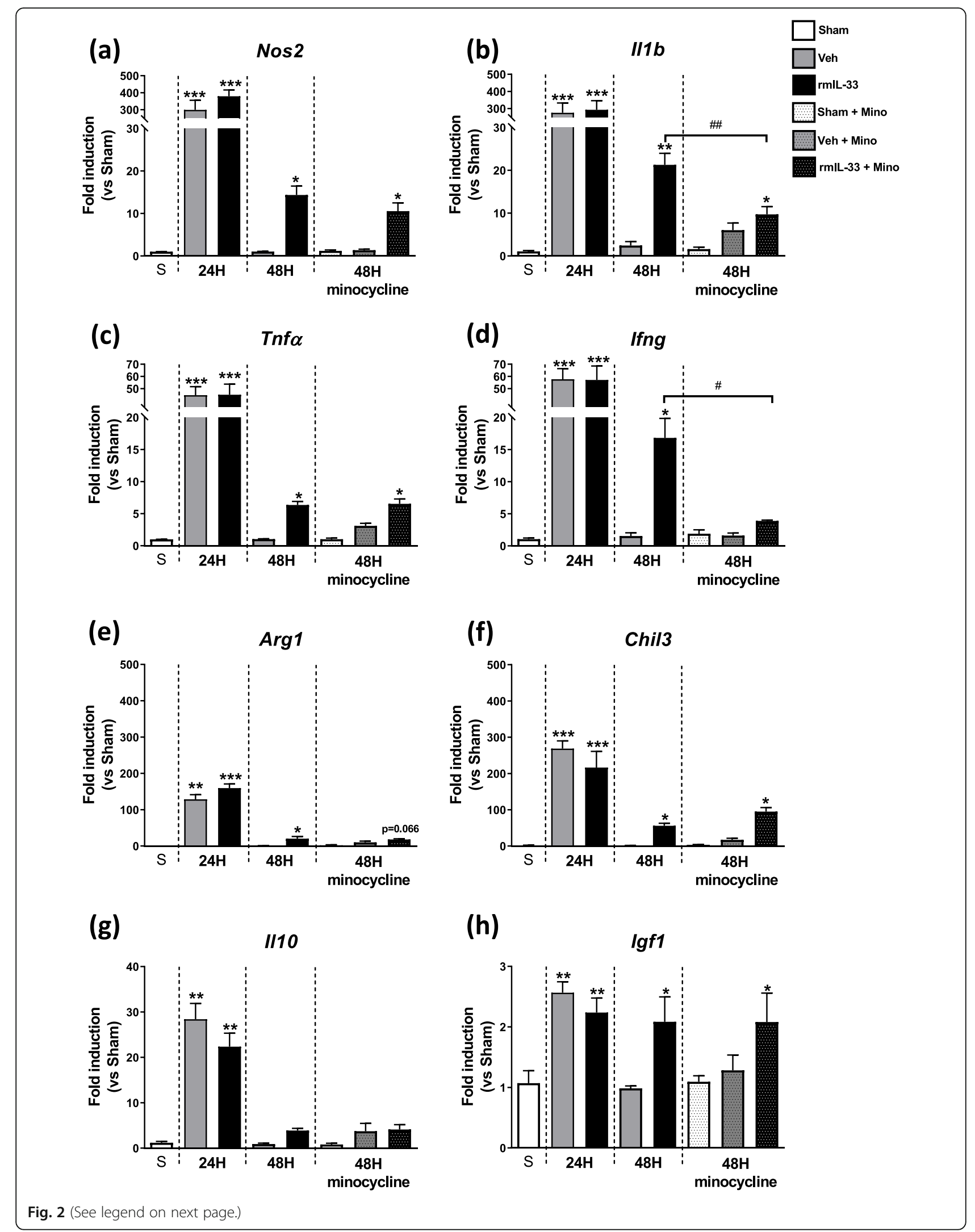


(See figure on previous page.)

Fig. 2 mRNA expression of inflammatory markers in hippocampi of IL-33-injected mice. mRNA expression of pro-inflammatory markers (Nos 2 in a,

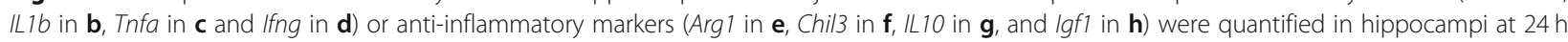
and $48 \mathrm{~h}$ post-surgery by RT-qPCR normalized against 185 RNA. Relative fold change in vehicle group (grey bar) and in rmlL-33 group (black bar) were quantified versus sham group (S; white bar). Minocycline-treated mice were also analyzed at $48 \mathrm{~h}$ post-surgery (dotted bar). IL-33 injection delayed the resolution of inflammation highlighted by an increase of inflammatory markers at $48 \mathrm{~h}$ administration. A partial reduction of this effect was observed under minocycline exposure, especially for $I L-16$ and Ifng mRNA. Data are represented as mean \pm SEM $(n=4-6)$. Statistical comparisons were made using Kruskal-Wallis followed by Dunn's multiple comparison test for each group vs. Sham. ${ }^{*} P \leq 0.05,{ }^{* *} P \leq 0.01,{ }^{* * *} P \leq$ 0.001. In addition, a comparison between rmlL-33 (48 h) and rmlL-33 + mino ( $48 \mathrm{~h})$ groups was performed using the Mann-Whitney test. \#P $\leq$ $0.05, \#$, $\# 0.01$

Immunochemistry experiments were performed to quantify the number of Iba- $1^{+}$microglial cells in the different hippocampal areas (Fig. 3a). After vehicle injection, there was no significant difference in the number of Iba- $1^{+}$cells in the cornu ammonis (CA), CA1/CA2 (Fig. 3b), CA3 (Fig. 3c), and the dentate gyrus (DG) (Fig. 3d), as compared to sham groups. However, the number of Iba- $1^{+}$ glial cells was increased after rmIL-33 administration in the three hippocampal areas. Interestingly, minocycline treatment prevented rmIL-33-induced increase of microglial cell numbers in all areas of the hippocampus. To go further, microglia activation was investigated at $48 \mathrm{~h}$ postinjection. Microglial cells exhibited a typical activated morphology $48 \mathrm{~h}$ after vehicle administration, as compared with sham controls and this activated phenotype was more prominent after rmIL-33 administration (Fig. 4a). The Sholl analysis was used to provide a quantitative assessment of glial cell activation in situ (Fig. 4b). We demonstrated an increase of proximal intersections per radius in the CA1/CA2, CA3, and the DG $48 \mathrm{~h}$ postinjection of vehicle, which was more pronounced after rmIL-33 treatment (Fig. 4b). Although hippocampal injection itself slightly modified microglia morphology, rmIL33 significantly promoted the outgrowth of microglial processes, in agreement with an activated state. This effect of rmIL-33 administration was prevented by minocycline pre-treatment in the three hippocampal areas analyzed (Fig. 4b, c). These findings show that rmIL-33 administration induced microglial activation and proliferation/recruitment in the hippocampus, and this effect was sensitive to the anti-inflammatory effect of minocycline.

\section{Hippocampal exogenous rmIL-33 induces an increase of microglial cells expressing pro-IL-1 $\beta$}

To dissect the effect of rmIL-33 on microglia functions, we performed flow cytometry on dissociated cells from hippocampal tissues, $48 \mathrm{~h}$ after vehicle or rmIL-33 treatment. We determined the frequency of microglia, macrophages, and lymphocytes in hippocampal samples from sham, vehicle- and rmIL-33-treated groups. The gating strategy of live cell analysis is shown (Fig. 5a). Group comparison showed an increasing trend of
$\mathrm{CD} 11 \mathrm{~b}^{\text {low }} / \mathrm{CD} 45^{\text {high }}$ cells defined as lymphocytes and $\mathrm{CD} 11 \mathrm{~b}^{+} / \mathrm{CD} 45^{\text {high }}$ cells defined as macrophages (Fig. $5 \mathrm{~b}$, c) after vehicle or rmIL-33 administration. However, there was an increase in terms of $\mathrm{CD} 11 \mathrm{~b}^{+} / \mathrm{CD} 45^{\text {low }}$ cells defined as microglial cells in rmIL-33-treated mice, as compared with vehicle control group (Fig. 5d), in agreement with the immunohistochemical data (Fig. 3). Moreover, intracellular staining using a pro-IL-1 $\beta$ specific antibody demonstrated overexpression of pro-IL-1 $\beta$ by hippocampal microglial cells exposed to rmIL-33 (Fig. $5 \mathrm{e}, \mathrm{f})$. Altogether, these data suggest that rmIL-33 induced an increase of hippocampal microglial cells expressing pro-IL-1 $\beta$.

\section{Exogenous rmIL-33-induced cognitive impairments require IL-1 signaling}

As rmIL-33 administration induced microglia proliferation/recruitment with IL-1 $\beta$ overexpression, we next questioned whether IL-1 contributes to the maintenance of inflammation and the cognitive disorders induced by exogenous rmIL-33. To address this question, we injected rmIL-33 in the hippocampus of mice deficient for IL- $1 \alpha$ and IL-1 $\beta$ (IL-1 $\alpha \beta^{-/-}$) and evaluated their responses in spatial memory tasks at $24 \mathrm{~h}$ and $48 \mathrm{~h}$ post-administration.

The decrease of distance traveled exhibited by vehicletreated-IL-1 $\alpha \beta^{-/-}$mice (Fig. 6a) was similar to WT mice at $24 \mathrm{~h}$ after rmIL-33 administration (Fig. 1b), indicating that IL- $1 \alpha \beta^{-1-}$ mice displayed as WT mice normal intrasession habituation. However, at $48 \mathrm{~h}$ post-rmIL-33 injection, the decrease in traveled distance indicating that IL- $1 \alpha \beta^{-1-}$ mice retained spatial memory retrieval (Fig. $6 \mathrm{~b})$, in contradiction with the rmIL-33-treated wild type mice, previously observed (Fig. 1c). Moreover, we showed that in the absence of IL- $1 \alpha \beta$, rmIL-33 treatment induced an increase in the expression of key inflammatory mediators in the hippocampus (Nos2, Tnfa, Ifng, Arg1, Chil3 and Il10) of IL-1 $\alpha \beta^{-1-}$ mice, $48 \mathrm{~h}$ post-injection (Fig. 6c-j) which is similar in WT mice (Fig. 2). These results indicate that hippocampal IL-1 expression, and most likely IL-1 $\beta$, is required for rmIL-33induced cognitive impairment independently of upstream inflammatory mediators. 


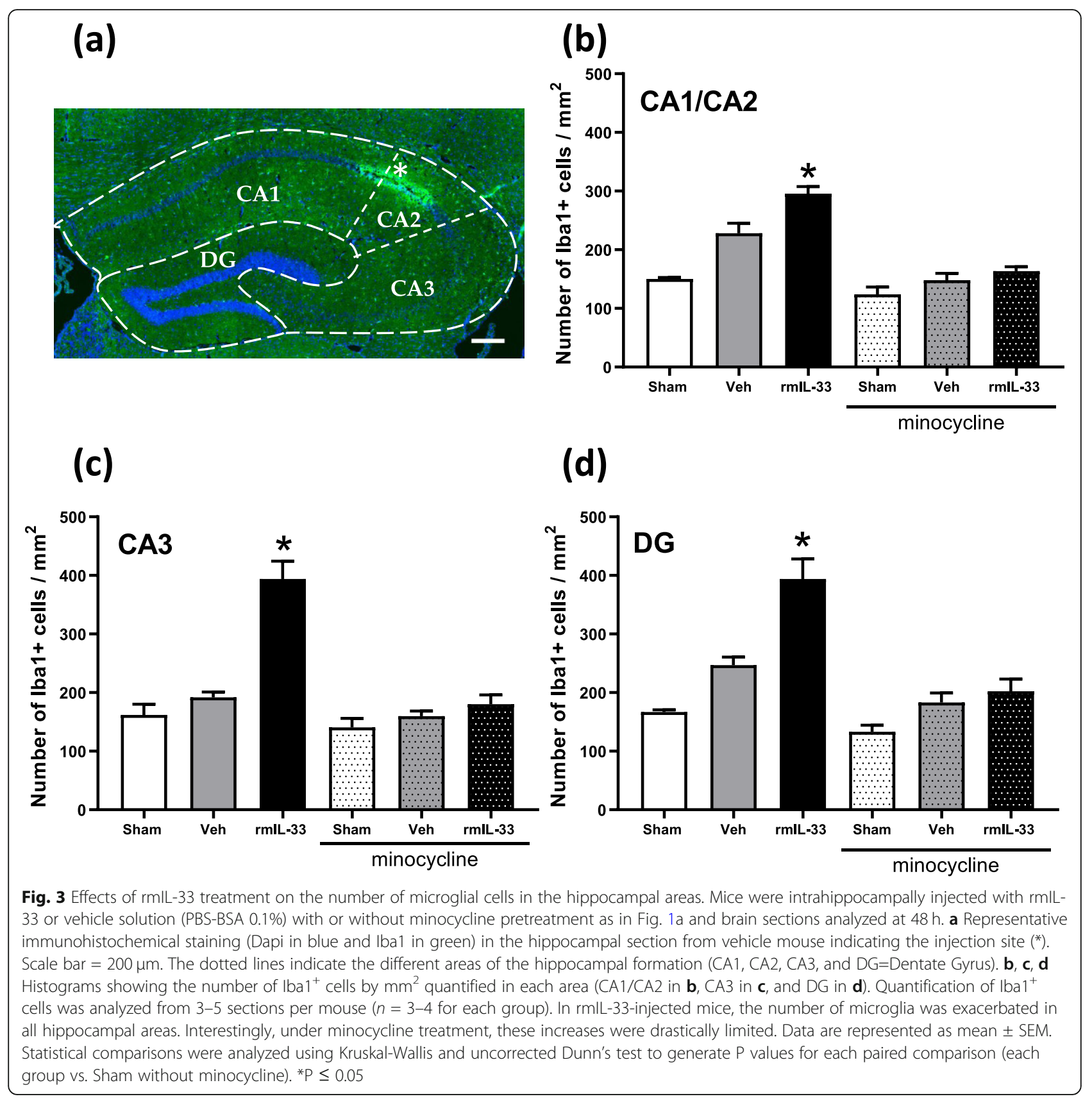

\section{Discussion}

The implications of IL-33 has been described in many neuropathologies [1], not only as protective $[14,16]$ but also as disruptor $[15,17]$ of neuronal homeostasis. IL-33 exerts pleiotropic effects on the immune system, both on type 2 and type 1 immune responses, in the periphery but also at the CNS level. Despite the presence of IL-33 in a healthy brain [4] and in CNS pathologies [1], the multifold functions of IL-33 in CNS remain unclear. To elucidate the role of endogenous IL-33 in the CNS, the present study explored the consequences of intrahippocampal injection of recombinant IL-33 on cognitive function and neuroinflammatory processes.

Using spatial habituation tasks in an open field, allowing to address hippocampal non-associative learning and memory processes $[19-21,26]$, we show that the habituation to a novel environment was intact in IL-33 hippocampal treated mice 1-day post-surgery. These results indicate that neither the micro-lesion induced by the injection nor the IL-33 treatment had a neurological impact on learning at this stage. However, $48 \mathrm{~h}$ after intrahippocampal injection, IL-33-treated mice displayed 
(a)
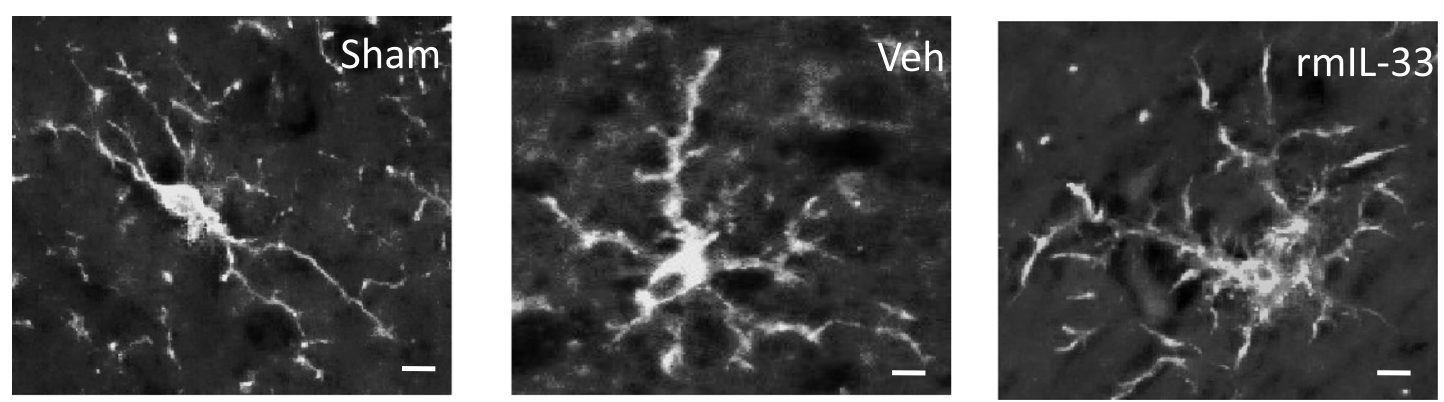

(b)

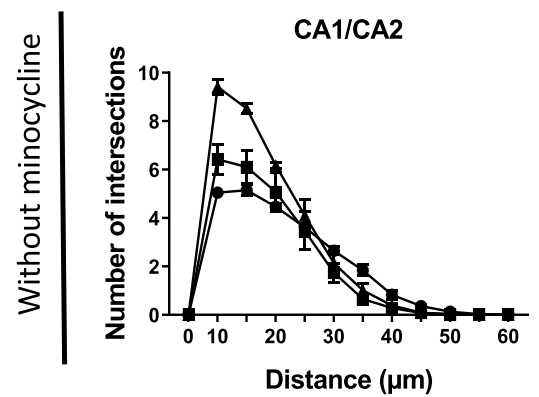

CA3

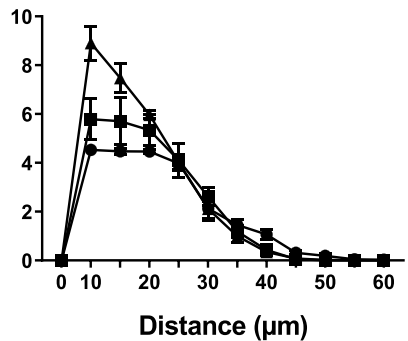

DG

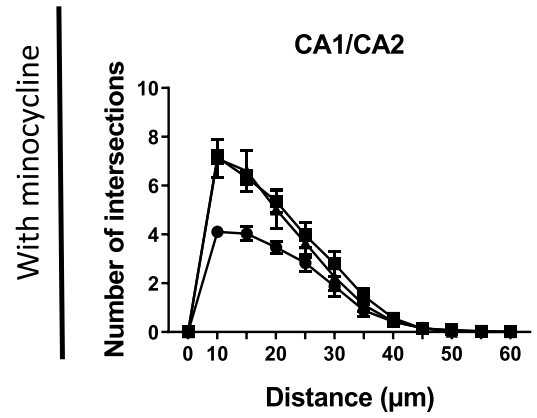

CA3

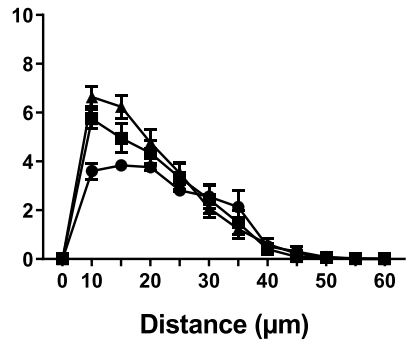

DG

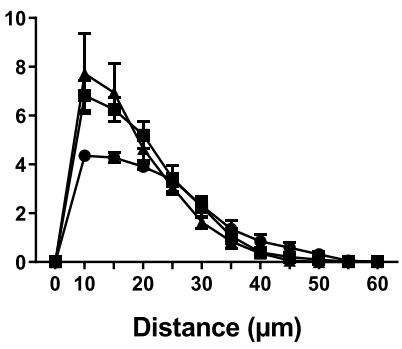

(c)
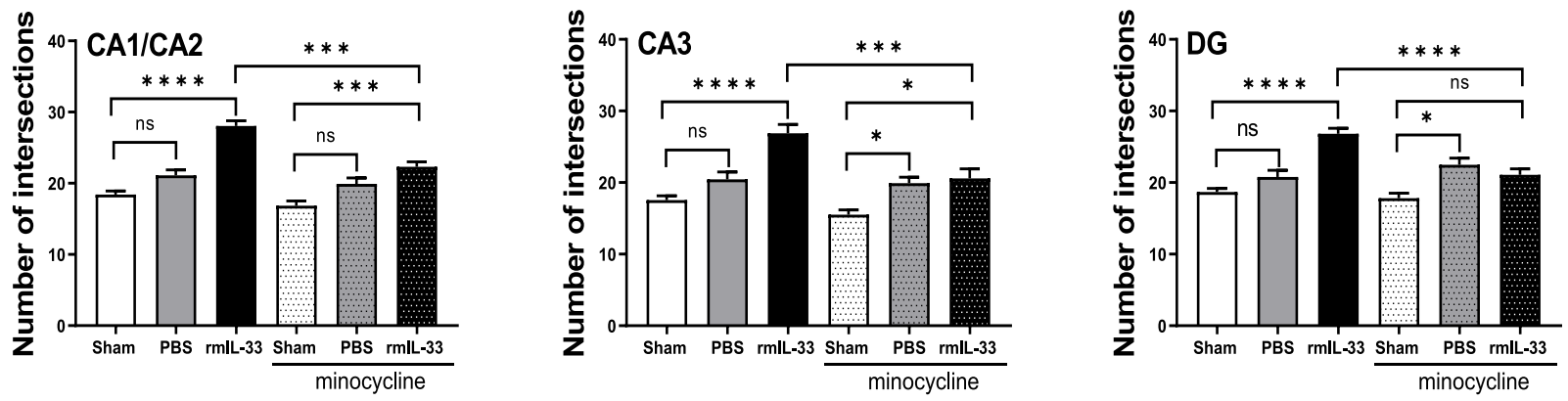

Fig. 4 Effects of rmlL-33 treatment on microglial morphology in hippocampal areas. a Representative high magnification of Iba $1^{+}$microglia in sham, vehicle- or rmIL-33-treated mice (Scale bar $=10 \mu \mathrm{m}$ ). b, c Sholl analysis was performed after Iba1 immunohistochemistry on the hippocampal section from $48 \mathrm{~h}$ post-surgery mice. $\mathbf{b}$ To evaluate the ramification complexity of microglial cells, the number of process intersections per radius was reported graphically in the curve. c Bar graphs show the cumulated number of intersections at distances up to $25 \mathrm{\mu m}$ from the soma. The analyses were performed for each hippocampal area and for each group without or with minocycline treatment. In all hippocampal areas, Sholl analysis showed that microglia maintained hyper-ramified state following IL-33 injection, although vehicle treatment induced an intermediate-ramified state, as compared to sham. The minocycline pre-treatment impaired IL-33 effect on microglial morphology. Data are represented as mean \pm SEM. Statistical comparisons were made using One-way ANOVA followed by Tukey's multiple comparison test. * $P$ $\leq 0.05,{ }^{* * *} P \leq 0.001,{ }^{* * *} P \leq 0.0001$ 


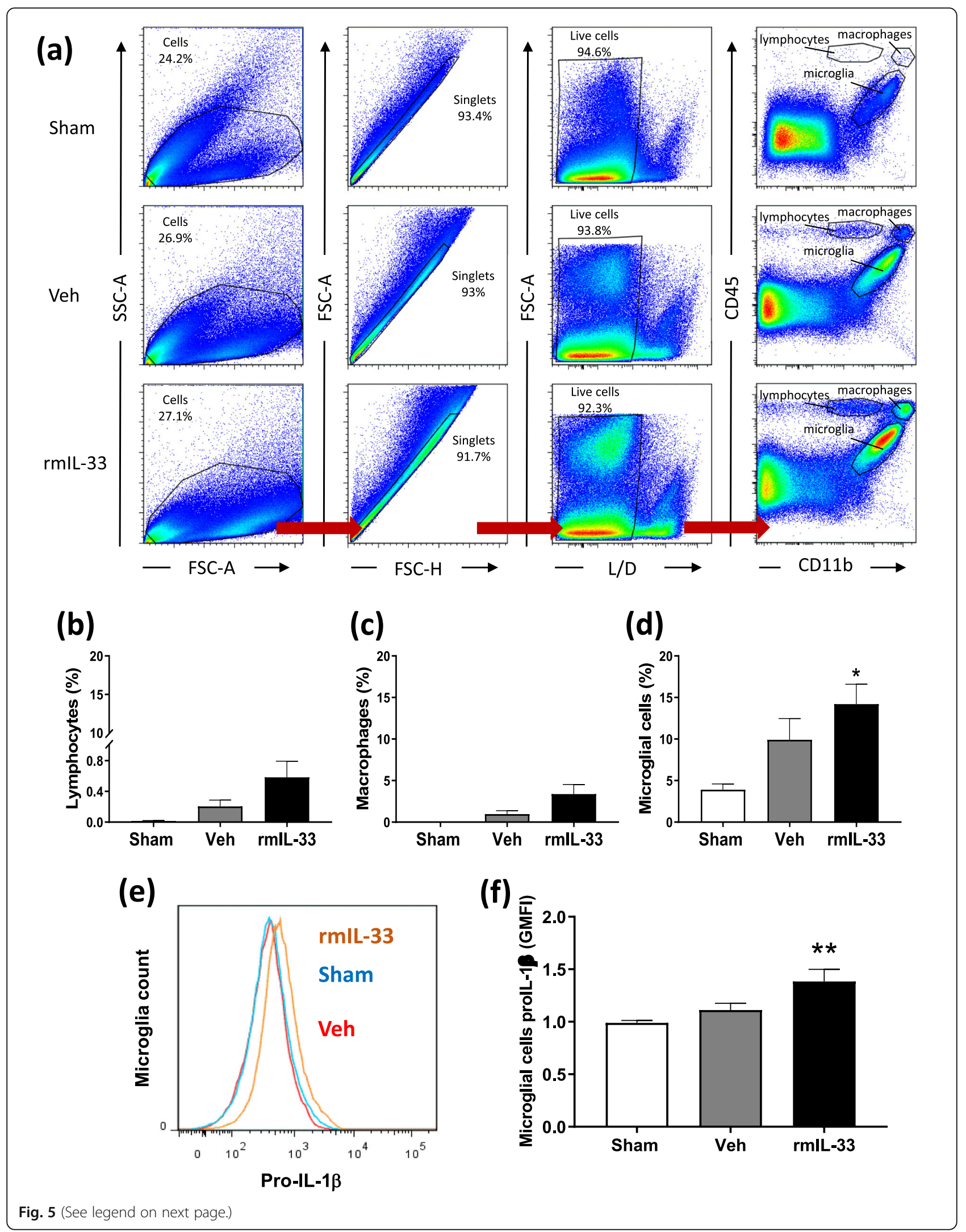




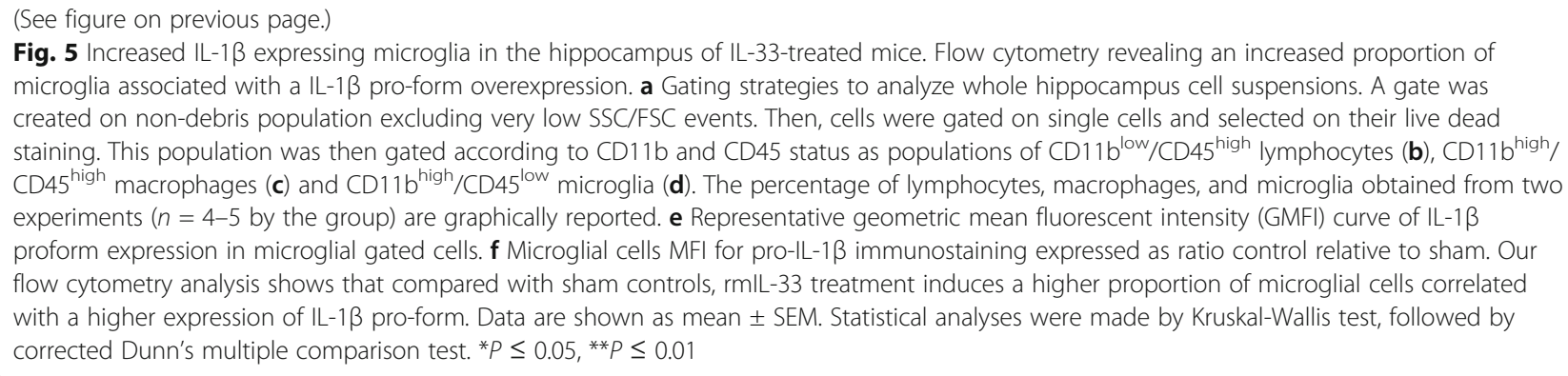

a complete impairment of spatial memory retrieval. Unlike control mice, they were not able to recognize the previously explored environment, indicating that longterm habituation was significantly affected after rmIL-33 administration. These results suggest that a massive IL33 release might disturb neuronal function and affect the memory retrieval process. IL-33 has been previously involved in cognitive defects observed in neuropathological conditions such as reflected in Alzheimer's disease, multiple sclerosis, and experimental cerebral malaria $[1,10,22]$. Our data further show that injecting recombinant IL-33 directly in the hippocampus could mimic an acute exposure of IL-33 and its effects on cognitive processes.

To explore the link between the cognitive defect induced by IL-33 and the neuroinflammatory response, mice were pre-treated with minocycline. This antibiotic is able to cross the blood-brain barrier and exhibits antiinflammatory properties preventing memory deficits in several neuropathologies [25]. In the present study, chronic administration of minocycline alone before intrahippocampal injections in control mice did not affect learning and spatial memory processes. However, our data also reveal that pre-treatment with minocycline seems to prevent the spatial memory retrieval impairment induced by IL-33 administration. This rescue of the IL-33-induced phenotype suggests that the cognitive impairments induced by IL-33 involved a neuroinflammatory process.

Previous studies demonstrated that IL-33/ST2 pathway modulated the production of cytokines and chemokines in neuropathological conditions [1, 3, 17]. We assessed the direct effects of IL-33 role on the inflammatory context by gene expression analysis. We quantified mRNA expression levels in the hippocampus of molecular markers usually used to define pro-inflammatory or regulatory immune response [27]. Nos2, Il1b, Tnfa, and Ifng are mediators of pro-inflammatory responses whereas Arg1, Chil3, Illo, and Igf1 are associated with immunoregulatory mechanisms. In control mice, we observed a transient inflammatory response induced by the injection at $24 \mathrm{~h}$ and resolving at $48 \mathrm{~h}$ post-injection.
This transient response to a slight trauma is correlated with the ability of the organism to return to a homeostasis state without adverse effects on behavior [28]. However, at $48 \mathrm{~h}$, the intrahippocampal IL-33 injection induced a neuroinflammatory environment with overexpression of pro-inflammatory and immunoregulatory markers mRNA. Minocycline administration reduced this inflammatory context in terms of Illb and Ifng expression at $48 \mathrm{~h}$, contributing to the resolution of inflammation. These results suggest that exogenous IL-33 induces a neuroinflammatory phenotype associated with long-term habituation disturbance.

To explore the cellular process involved in IL-33induced immune response, we focused on microglia, the first active immune barrier in the CNS strongly expressing IL-33 receptor ST2 [14]. We investigated the hippocampal microglia reaction by immunochemistry using Iba-1 staining. Indeed, in response to a neuroinflammatory context induced by LPS administration, resident microglia alter their shape in a specific way as compared with infiltrated peripheral cells with a rounder morphology [29, 30]. Sholl analysis on Iba1 immunofluorescent staining revealed a significant increase of proximal intersections per radius in the CA1/CA2, CA3, and DG regions $48 \mathrm{~h}$ after IL-33 treatment. This reactive morphology associated with an increase of microglial cell number demonstrated maintenance of their activated state. Minocycline administration through its antiinflammatory activity attenuated the microglia activation of IL-33 treated mice, in line with previous reports in cognitive disorders [31, 32]. This result suggests that the deleterious function of IL-33 pathway on spatial memory retrieval processes requires microglia activation, especially in the hippocampal formation. Indeed, in healthy conditions, microglia regulate neuronal activity, synaptic plasticity, and adult neurogenesis required for learning and memory. In many neuropathologies, the microglia reactivity state has been characterized based on morphological modifications and the release of cytokines, chemokines, and growth factors, modulating neuronal and synaptic functions. This activated phenotype should be beneficial and associated with inflammatory changes 
(a)

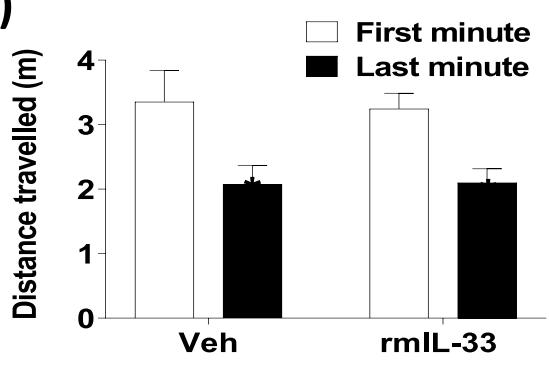

(c)

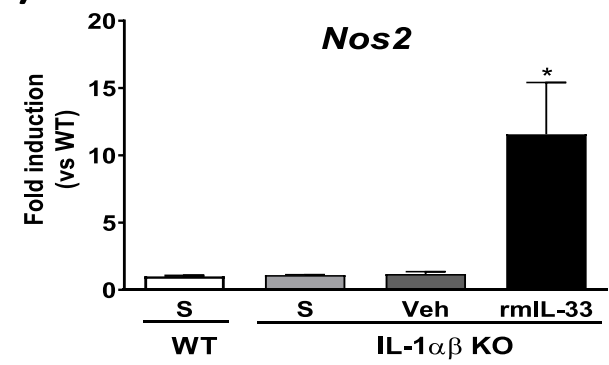

(e)

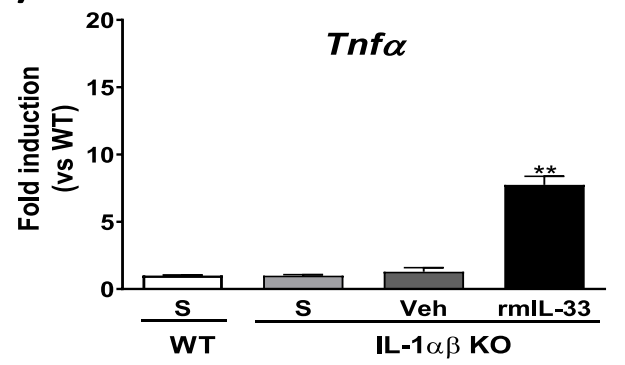

(g)

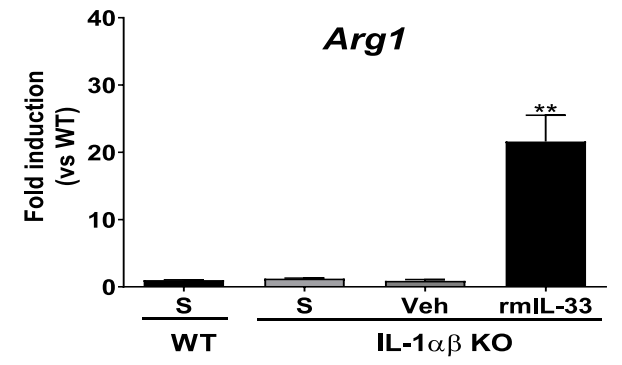

(I)

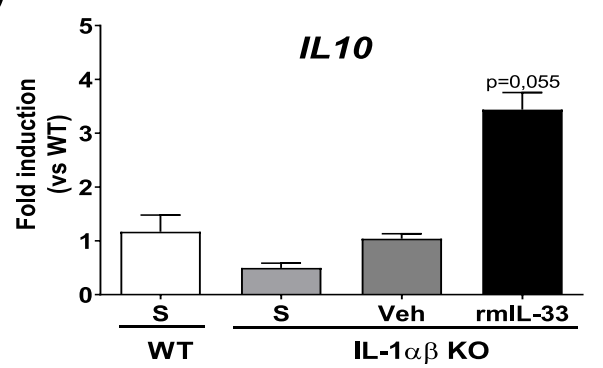

(b)

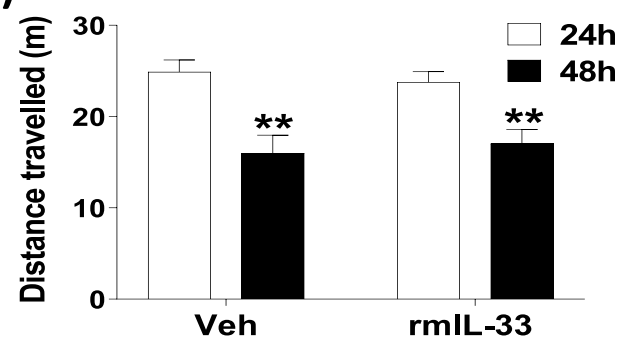

(d)

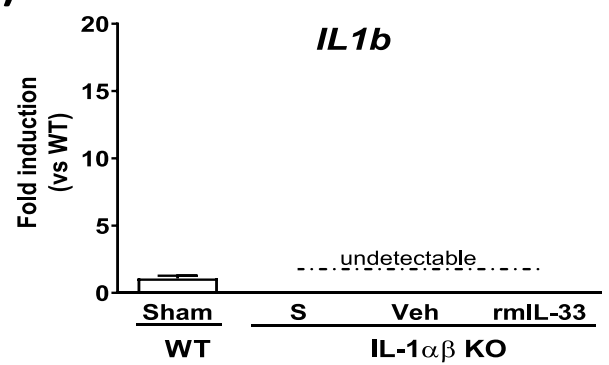

(f)

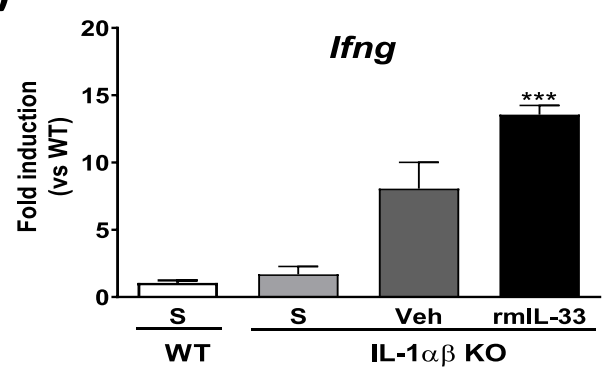

(h)

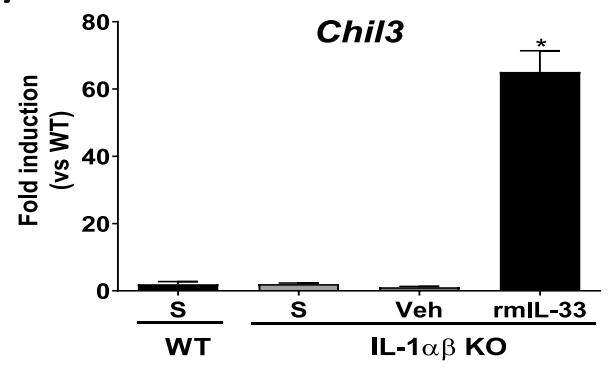

(J)

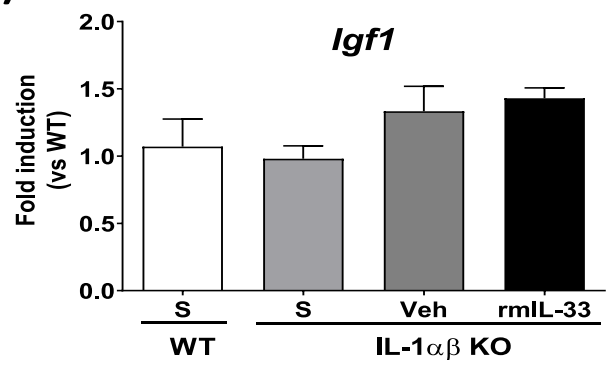

Fig. 6 (See legend on next page.) 
(See figure on previous page.)

Fig. 6 Effects of hippocampal exogenous IL-33 on spatial memory and habituation and hippocampi mRNA expression in IL-1aß KO mice. IL-1aß KO mice were intrahippocampally injected with rmIL-33 or vehicle solution (PBS-BSA $0.1 \%$ ). Habituation in a novel environment was analyzed in intrasession (a) and in intersession $24 \mathrm{~h}$ and $48 \mathrm{~h}$ post-surgery (b). mRNA expression of pro-inflammatory markers (Nos2 in c, II1b in $\mathbf{d}$, Thfa in $\mathbf{e}$, and Ifng in $\mathbf{f}$ ) or anti-inflammatory markers ( $\operatorname{Arg} 1$ in $\mathbf{g}$, Chil3 in $\mathbf{h}, \| 10$ in $\mathbf{i}$, and Igf1 in $\mathbf{j}$ ) was quantified by RT-qPCR normalized against $18 S$ RNA at $48 \mathrm{~h}$ post-administration in WT/sham (WT-S), IL-1aß KO/sham, IL-1a $\mathrm{KO} /$ vehicle and IL-1aß KO/rmIL-33-treated groups $(n=4-6)$. Relative fold change in groups was quantified versus WT/sham group (S; white bar). Data are shown as mean \pm SEM. The habituation analysis $(\mathbf{a}, \mathbf{b}), n=8-10$ per group corresponding to a pool of 2 independent experiments. Two-way ANOVA followed by a Sidak post hoc test was used to analyze the distance traveled among the two groups (IL-1 a $\beta$ KO injected with vehicle or rmlL-33). For qPCR analysis, statistical comparisons were made using Kruskal-Wallis followed by Dunn's multiple comparison test for each group vs. WT/Sham. ${ }^{*} P \leq 0.05,{ }^{* *} P \leq 0.01,{ }^{* * *} P \leq 0.001$

to combat the injury and return to a homeostatic state. However, these defense processes could be overstimulated and cause significant damage to behavior [33], as we demonstrated hereafter intrahippocampal IL33 injection.

To confirm the IL-33-induced microglial reactivity, cells from the hippocampi of IL-33-treated mice were analyzed by flow cytometry at $48 \mathrm{~h}$ post-surgery. Although neither macrophage nor lymphocyte recruitment was observed, microglia number was significantly increased in IL-33-treated mice, confirming our immunohistological data. This analysis revealed also an overexpression of the IL-1 $\beta$ immature form in hippocampal microglia $48 \mathrm{~h}$ after IL-33 injection. Thus, in vivo, IL-33 treatment promotes IL- $1 \beta$ microglia production, as previously demonstrated in vitro [10], indicating that microglia contribute to the pro-inflammatory response. We then hypothesized that the cognitive impairment induced by exogenous IL-33 may be mediated in part by microglia derived IL-1. To test this point, we performed IL-33 intrahippocampal microinjections in IL- $1 \alpha \beta$ deficient mice. The absence of IL-1 cytokines prevented spatial memory retrieval impairment induced by IL-33 administration even if neuroinflammatory markers, except IL-1 $\beta$ and IL- $1 \alpha$, were upregulated. Thus, IL-1 $\beta$ producing microglia are required for IL-33 neurotoxic effects on cognitive impairment. In our experimental conditions, IL-1 contribution to these cognitive defects impairment could involve its non-immunological activities. Indeed, this cytokine has been described as critical for learning and memory in a dose-dependent manner [34]. Here, we verified that IL- $1 \alpha \beta$ deficient mice behave as WT mice in terms of habituation to spatial novelty in our experimental conditions. Prolonged up-regulation of pro-inflammatory cytokines, especially IL-1 $\beta$, has been associated with a decrease in synaptic plasticity, as well as a deficit in spatial learning $[35,36]$. This IL- $1 \beta$ disruptive effect on cognitive functions could involve the inhibition of long-term potentiation generation at the neuronal level and/or defect of neurotrophic factors production [34]. All these parameters should be further investigated in our futures studies.

\section{Conclusion}

In conclusion, we showed that IL-33 intrahippocampal administration is a valuable tool to mimic a local acute exposition. We provide the evidence that CNS IL-33 directly orchestrates neuroinflammatory mechanisms through microglia activation and overproduction of IL1 -inducing spatial memory disorders. Thus, we suggest that in neuropathological conditions IL-33 released by astrocytes and/or oligodendrocytes may activate microglia and induce IL-1-dependent cognitive defects. These results highlight the need to dissociate the CNS versus systemic IL-33 effects, in particular in the context of cerebral diseases.

\section{Supplementary information}

Supplementary information accompanies this paper at https://doi.org/10. 1186/s12974-020-01939-6.

Additional file 1. The emotional state of mice was tested $24 \mathrm{H}$ after the intrahippocampal microinjection. Anxiety-like behavior, representing by the time spent in center of the open field, was not different between: (a) mice intrahippocampal injected with vehicle solution (Veh) versus rmIL33, (b) mice intrahippocampal injected with vehicle solution versus rmlL33 treated with minocycline, (c) IL-1 a $\beta$ KO mice intrahippocampal injected with vehicle solution versus rmlL-33. Values are mean \pm SEM, $n$ =8-15 per group, Mann-Whitney test was used to compare the time spent in the center between 2 groups.

Additional file 2. Expression of IL-1a mRNA in hippocampi at $24 \mathrm{~h}$ and $48 \mathrm{~h}$ post-surgery, in Sham, vehicle or IL-33 intra-hippocampal treated mice with or without minocycline pretreatment. mRNA expression of the pro-inflammatory marker IL-1a was quantified in hippocampi by RT-qPCR normalized against 18S RNA. Relative fold change in vehicle group (grey bar) and in IL-33 group (black bar) were quantified versus sham group (S ; white bar). Minocycline treated mice were also analyzed at $48 \mathrm{~h}$ postsurgery (dotted bar). IL-33 injection delayed the resolution of inflammation highlighted by an increase of this markers at $48 \mathrm{~h}$ administration. A partial reduction of this effect was observed under minocycline exposure. Data are represented as mean \pm SEM $(n=4-6)$. Statistical comparisons were made using Kruskal-Wallis followed by Dunn's multiple comparison test for each group vs. Sham. ${ }^{* *} p \leq 0.01$, ${ }^{* * *} p \leq 0.001$. In addition, comparison between rmlL-33 (48 h) and rmlL-33 + mino (48 h) groups was performed using the Mann-Whithney test.

\section{Acknowledgements}

The authors thank Dr. Marc Le Bert for expert advice in mouse genetics, Mr. David Gosset, responsible of the Cytometry and cellular imaging P@CYFIC platform, and Dr. Jean-Charles Bizot, Key-Obs company director for stereotaxic equipment. 


\section{Authors' contributions}

$F R$, VdC, and VL performed the experiments; FR, Vd.C, DT, and AM conceived the experiments and analyzed the data; $F R, V d C, V Q$, and $A M$ discussed the results and prepared the paper. SB, BR, VQ provided funding, and AM overall supervision of this study. All authors read and approved the final manuscript.

\section{Funding}

This work was supported by CNRS, the University of Orleans, and European funding in the Region Centre-Val de Loire (FEDER N²016-00110366 and EX005756).

\section{Availability of data and materials}

The datasets used and/or analyzed during the current study are available from the corresponding author on reasonable request.

\section{Ethics approval and consent to participate}

All animal experimental protocols complied with the French ethical and animal experiments regulations and were approved under number APAFIS $\# 19264$

\section{Consent for publication}

Not applicable.

\section{Competing interests}

The authors declare that they have no competing interests

\section{Author details}

'UMR7355, Experimental and Molecular Immunology and Neurogenetics, CNRS and University of Orléans, 3B rue de la Ferollerie, 45071 Orléans, France. ${ }^{2}$ Current address: Center for Molecular Biophysics, CNRS UPR4301, 45071 Orléans, France. ${ }^{3}$ Current address:Department of Urology, Urology Research Unit, CHUV, Lausanne, Switzerland. ${ }^{4}$ Department of Genetics, Regional Hospital, Orléans, France. ${ }^{5}$ Artimmune SAS, 13 Avenue Buffon, 45071 Orléans-Cedex 2, France.

\section{Received: 6 April 2020 Accepted: 24 August 2020}

\section{Published online: 11 September 2020}

\section{References}

1. Liew FY, Girard JP, Turnquist HR. Interleukin-33 in health and disease. Nat Rev Immunol. 2016;16(11):676-89.

2. Abd Rachman Isnadi MF, Chin VK, Abd Majid R, Lee TY, Atmadini Abdullah $M$, Bello Omenesa R, et al. Critical Roles of IL-33/ST2 Pathway in neurological disorders. Mediators Inflamm. 2018:2018:5346413.

3. Du L, Hu X, Yang W, Yasheng H, Liu S, Zhang W, et al. Spinal IL-33/ST2 signaling mediates chronic itch in mice through the astrocytic JAK2-STAT3 cascade. Glia. 2019;67(9):1680-93.

4. Hudson CA, Christophi GP, Gruber RC, Wilmore JR, Lawrence DA, Massa PT. Induction of IL-33 expression and activity in central nervous system glia. J Leukoc Biol. 2008;84(3):631-43.

5. Li M, Li Y, Liu X, Gao X, Wang Y. IL-33 blockade suppresses the development of experimental autoimmune encephalomyelitis in C57BL/6 mice. J Neuroimmunol. 2012;247(1-2):25-31.

6. Allan D, Fairlie-Clarke KJ, Elliott C, Schuh C, Barnett SC, Lassmann H, et al. Role of IL-33 and ST2 signalling pathway in multiple sclerosis: expression by oligodendrocytes and inhibition of myelination in central nervous system. Acta Neuropathol Commun. 2016;4(1):75.

7. Xiong Z, Thangavel R, Kempuraj D, Yang E, Zaheer S, Zaheer A. Alzheimer's disease: evidence for the expression of interleukin-33 and its receptor ST2 in the brain. J Alzheimers Dis. 2014;40(2):297-308.

8. Saresella M, Marventano I, Piancone F, La Rosa F, Galimberti D, Fenoglio C, et al. IL-33 and its decoy SST2 in patients with Alzheimer's disease and mild cognitive impairment. J Neuroinflammation. 2020;17(1):174.

9. Palomo J, Reverchon F, Piotet J, Besnard AG, Couturier-Maillard A, Maillet I, et al. Critical role of IL-33 receptor ST2 in experimental cerebral malaria development. Eur J Immunol. 2015:45(5):1354-65.

10. Reverchon F, Mortaud S, Sivoyon M, Maillet I, Laugeray A, Palomo J, et al. IL33 receptor ST2 regulates the cognitive impairments associated with experimental cerebral malaria. PLoS Pathog. 2017;13(4):e1006322.
11. Shibui A, Takamori A, Tolba MEM, Nambu A, Shimura E, Yamaguchi S, et al. IL-25, IL-33 and TSLP receptor are not critical for development of experimental murine malaria. Biochem Biophys Rep. 2016;5:191-5.

12. Strangward P, Haley MJ, Albornoz MG, Barrington J, Shaw T, Dookie R, et al. Targeting the IL33-NLRP3 axis improves therapy for experimental cerebral malaria. Proc Natl Acad Sci U S A. 2018;115(28):7404-9.

13. Besnard AG, Guabiraba R, Niedbala W, Palomo J, Reverchon F, Shaw TN, et al. IL-33-mediated protection against experimental cerebral malaria is linked to induction of type 2 innate lymphoid cells, M2 macrophages and regulatory T cells. PLoS Pathog. 2015;11(2):e1004607.

14. Yang Y, Liu H, Zhang H, Ye Q, Wang J, Yang B, et al. ST2/LL-33-dependent microglial response limits acute ischemic brain injury. J Neurosci. 2017; 37(18):4692-704.

15. Yasuoka S, Kawanokuchi J, Parajuli B, Jin S, Doi Y, Noda M, et al. Production and functions of IL-33 in the central nervous system. Brain Res. 2011;1385:8-17.

16. Gadani SP, Walsh JT, Smirnov I, Zheng J, Kipnis J. The glia-derived alarmin IL-33 orchestrates the immune response and promotes recovery following CNS injury. Neuron. 2015;85(4):703-9.

17. Cao K, Liao X, Lu J, Yao S, Wu F, Zhu X, et al. IL-33/ST2 plays a critical role in endothelial cell activation and microglia-mediated neuroinflammation modulation. J Neuroinflammation. 2018;15(1):136.

18. Yamada H, Mizumo S, Horai R, Iwakura Y, Sugawara I. Protective role of interleukin-1 in mycobacterial infection in IL-1 alpha/beta double-knockout mice. Lab Invest. 2000;80(5):759-67.

19. Leussis MP, Bolivar VJ. Habituation in rodents: a review of behavior, neurobiology, and genetics. Neurosci Biobehav Rev. 2006;30(7):1045-64.

20. Vianna MR, Alonso M, Viola H, Quevedo J, de Paris F, Furman M, et al. Role of hippocampal signaling pathways in long-term memory formation of a nonassociative learning task in the rat. Learn Mem. 2000;7(5):333-40.

21. Bolivar VJ. Intrasession and intersession habituation in mice: from inbred strain variability to linkage analysis. Neurobiol Learn Mem. 2009; 92(2):206-14

22. Fu AK, Hung KW, Yuen MY, Zhou X, Mak DS, Chan IC, et al. IL-33 ameliorates Alzheimer's disease-like pathology and cognitive decline. Proc Natl Acad Sci U S A. 2016;113(19):E2705-13.

23. Bustin SA, Benes V, Garson JA, Hellemans J, Huggett J, Kubista M, et al. The MIQE guidelines: minimum information for publication of quantitative realtime PCR experiments. Clin Chem. 2009;55(4):611-22.

24. Schindelin J, Arganda-Carreras I, Frise E, Kaynig V, Longair M, Pietzsch T, et al. Fiji: an open-source platform for biological-image analysis. Nat Methods. 2012:9(7):676-82.

25. Moller T, Bard F, Bhattacharya A, Biber K, Campbell B, Dale E, et al. Critical data-based re-evaluation of minocycline as a putative specific microglia inhibitor. Glia. 2016;64(10):1788-94.

26. Pavkovic Z, Milanovic D, Ruzdijic S, Kanazir S, Pesic V. The influence of propofol anesthesia exposure on nonaversive memory retrieval and expression of molecules involved in memory process in the dorsal hippocampus in peripubertal rats. Paediatr Anaesth. 2018;28(6):537-46.

27. Orihuela R, McPherson CA, Harry GJ. Microglial M1/M2 polarization and metabolic states. Br J Pharmacol. 2016;173(4):649-65.

28. Buckley CD, Gilroy DW, Serhan CN, Stockinger B, Tak PP. The resolution of inflammation. Nat Rev Immunol. 2013:13(1):59-66.

29. David S, Kroner A. Repertoire of microglial and macrophage responses after spinal cord injury. Nat Rev Neurosci. 2011;12(7):388-99.

30. Herber DL, Maloney JL, Roth LM, Freeman MJ, Morgan D, Gordon MN. Diverse microglial responses after intrahippocampal administration of lipopolysaccharide. Glia. 2006;53(4):382-91.

31. Kobayashi K, Imagama S, Ohgomori T, Hirano K, Uchimura K, Sakamoto K, et al. Minocycline selectively inhibits M1 polarization of microglia. Cell Death Dis. 2013:4:e525.

32. Seabrook TJ, Jiang L, Maier M, Lemere CA. Minocycline affects microglia activation, Abeta deposition, and behavior in APP-tg mice. Glia. 2006;53(7): $776-82$

33. Szepesi Z, Manouchehrian O, Bachiller S, Deierborg T. Bidirectional Microglia-Neuron Communication in Health and Disease. Front Cell Neurosci. 2018;12:323.

34. Liu X, Quan N. Microglia and CNS Interleukin-1: Beyond Immunological Concepts. Front Neurol. 2018;9:8.

35. Oitzl MS, van Oers H, Schobitz B, de Kloet ER. Interleukin-1 beta, but not interleukin-6, impairs spatial navigation learning. Brain Res. 1993;613(1):160-3. 
36. Hein AM, Stasko MR, Matousek SB, Scott-McKean JJ, Maier SF, Olschowka JA, et al. Sustained hippocampal IL-1 beta overexpression impairs contextual and spatial memory in transgenic mice. Brain Behav Immun. 2010;24(2):243-53.

\section{Publisher's Note}

Springer Nature remains neutral with regard to jurisdictional claims in published maps and institutional affiliations.

Ready to submit your research? Choose BMC and benefit from:

- fast, convenient online submission

- thorough peer review by experienced researchers in your field

- rapid publication on acceptance

- support for research data, including large and complex data types

- gold Open Access which fosters wider collaboration and increased citations

- maximum visibility for your research: over $100 \mathrm{M}$ website views per year

At $B M C$, research is always in progress.

Learn more biomedcentral.com/submissions 